\title{
Effect of Hoof Trimming before the Dry Period on Productive Performance in Perinatal Dairy Cows
}

\author{
Takaaki ANDO')*, Atsushi ANNAKA ${ }^{1)}$, Hiromichi OHTSUKA ${ }^{1)}$, Masayuki KOHIRUIMAKI'), Tomohito HAYASHI), \\ Yoshihisa HASEGAWA ${ }^{1)}$ and Daisaku WATANABE ${ }^{1)}$ \\ ${ }^{1)}$ School of Veterinary Medicine, Kitasato University, Towada, Aomori 034-8628, ${ }^{2)}$ Kohiruimaki Animal Medical Service, Tohoku, \\ Aomori 039-2683 and ${ }^{3)}$ Research Institute for Biological Sciences, Tokyo University of Science, Noda, Chiba 278-0022, Japan
}

(Received 31 May 2007/Accepted 29 August 2007)

ABSTRACT. To investigate the effect of hoof trimming before the dry period, the hooves of 10 cows (trimmed group) were trimmed at $79.6 \pm 8.6$ days before parturition and the hooves of 52 cows were left untrimmed (control group). Blood biochemistry and hormone concentrations were investigated for 6 cows from each group. The daily milk yield after parturition in the trimmed group tended to be higher than that of the control group. Between 0 and 30 days after parturition, the levels of non-esterified fatty acids were significantly lower stet, and the plasma glucose and glucose disposal rates were significantly higher in the trimmed group. The plasma cortisol concentration was stable before and after parturition in the trimmed group. Hoof trimming before the dry period appears to reduce stress and maintain the nutritional conditions of perinatal dairy cows.

KEY WORDS: hoof trimming, nutrition, perinatal dairy cow.

J. Vet. Med. Sci. 70(1): 95-98, 2008

In recent years, improved management of dairy cows has increased milk production. In contrast, the average usable life of dairy cows is decreasing due to a variety of factors, such as locomotor disorders, metabolic disease, reproductive disorders and mastitis [19]. The condition of hooves is influenced by a number of factors, including nutrition, stress, environmental conditions and hoof trimming $[5,15$, 20]. Hoof trimming decreases hoof disease and reduces stress by stabilizing weight-bearing limbs $[3,14]$. The number of days from calving to conception can increase in dairy cows suffering from stress due to milk fever or lameness [1]. Thus, hoof trimming, which reduces stress and stabilizes feeding, improves milk yield and enhances reproductive performance [4]. However, inadequate or poor trimming may cause lameness [19], and it is therefore necessary to be performed by practitioners of hoof trimming. Previous studies have reported that trimming has positive effects in relation to reduction of hoof disorder [18] and improvement of productivity [2, 5, 12]. However, there have been very few investigations of its effect on nutrition and endocrine function. The aim of this study was to investigate the effect of hoof trimming before the dry period on body condition, reproductive performance, milk yield, blood biochemistry and hormone concentrations before and after parturition.

Holstein dairy cows that were housed in a tie stall barn under natural light and temperature conditions were divided into two groups; the trimmed groups contained cows $(n=10)$ whose hooves were trimmed between days 61 to $90(79.6 \pm$ 8.6 days) and the control group contained cows $(n=52)$ whose hooves were left. None of the cows had any clinical abnormality, and hoof trimming was not performed for

\footnotetext{
* Correspondence to: Ando, T., Department of Large Animal Surgery, School of Veterinary Medicine, Kitasato University, 35-1 Higashi 23 ban-cho, Towada, Aomori 034-8628, Japan.

e-mail: ando@vmas.kitasato-u.ac.jp
}

more than one year before this study. The experimental period covered 2 months before and 4 months after parturition (day $0=$ parturition) and was divided into the following 5 periods: days -60 to -31 , days -30 to -1 , days 0 to 30 , days 31 to 60 and days 61 to 120 . Body weight (BW), weight change rate (WCR) and body condition score (BCS) were measured monthly. Daily milk yield and reproductive state after parturition were also investigated. BW was measured by estimation tape, and both BCS and WCR were calculated according to previously reported methods [7]. The feed contents between days -60 to -30 , days -30 to -1 and days 0 to 120 were evaluated according to National Research Council (NRC) 2001 standards. At each monthly examination, blood samples were collected from 6 cows in each group between 2 and 4 p.m., at least 2 hr after feeding commenced. For blood chemistry analysis, plasma samples were analyzed for glucose (Glu, GOD method), total cholesterol (T-chol, CHOD/PAP method), urea nitrogen (UN, urease-GLDH method), and non-esterified fatty acids (NEFA, enzymatic UV method). The plasma cortisol concentration was determined in accordance with the modified of enzyme immunoassay of Kumari [9], while the plasma insulin concentration was determined in accordance with the timeresolved competitive immunoassay of Lovendahl [10]. The intra- and inter-assay coefficients of variation were $3.3 \%$ and $4.2 \%$ for cortisol and $2.7 \%$ and $3.1 \%$ for insulin, respectively. An insulin tolerance test was performed to measure the insulin-stimulated glucose disposal rate (GDR), which was calculated according to previously reported methods [13]. Statistical analysis was performed using Mann-Whitney's $U$ test for each milking stage in the two groups, and values of $\mathrm{p}<0.05$ were regarded as significant. All data were expressed as means $\pm \mathrm{SD}$.

No significant differences were observed in the BW, WCR and BCS of the trimmed and control groups through- 
Table 1. Comparison of the body weights, weight change rates and body condition scores of the trimmed and control groups

\begin{tabular}{ccrr}
\hline \multirow{2}{*}{ Variable } & $\begin{array}{c}\text { Milking stage } \\
\text { (days) }\end{array}$ & \multicolumn{2}{c}{ Groups } \\
\cline { 2 - 4 } & \multicolumn{1}{c}{ Trimmed } & \multicolumn{1}{c}{ Control } \\
\hline BW & -60 to -31 & $687.8 \pm 49.1$ & $686.8 \pm 24.5$ \\
$(\mathrm{~kg})$ & -30 to -1 & $692.7 \pm 47.3$ & $681.4 \pm 19.4$ \\
& 0 to 30 & $630.8 \pm 22.5$ & $634.1 \pm 34.1$ \\
& 31 to 60 & $597.9 \pm 63.6$ & $600.5 \pm 20.2$ \\
& 61 to 120 & $615.3 \pm 26.6$ & $613.2 \pm 19.5$ \\
WCR & -60 to -31 & $1.70 \pm 6.26$ & $2.43 \pm 6.53$ \\
$(\%)$ & -30 to -1 & $0.71 \pm 5.95$ & $-0.80 \pm 5.60$ \\
& 0 to 30 & $-9.81 \pm 4.48$ & $-7.46 \pm 8.64$ \\
& 31 to 60 & $-5.51 \pm 8.28$ & $-5.59 \pm 7.29$ \\
BCS & 61 to 120 & $2.83 \pm 6.22$ & $2.07 \pm 5.74$ \\
& -60 to -31 & $3.23 \pm 0.58$ & $3.06 \pm 0.82$ \\
& -30 to -1 & $3.11 \pm 0.53$ & $3.11 \pm 0.73$ \\
& 0 to 30 & $2.65 \pm 0.56$ & $2.55 \pm 0.96$ \\
& 31 to 60 & $2.47 \pm 0.62$ & $2.45 \pm 0.77$ \\
& 61 to 120 & $2.59 \pm 0.72$ & $2.42 \pm 0.62$ \\
\hline
\end{tabular}

Values are expressed as means \pm SD.

BW: body weight. WCR: weight change rate. BCS: body condition score.

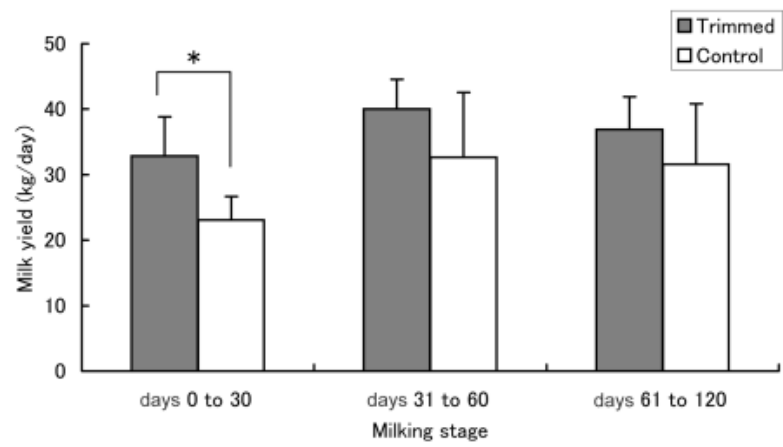

Fig. 1. Comparison of the daily milk yield of the trimmed and control groups. *: Significant difference between the groups $(\mathrm{p}<0.05)$.

out the experimental period (Table 1). The day of first estrus, conception rate following first artificial insemination and number of days from calving to conception after parturition were not significantly different between the groups. The daily milk yield of the trimmed group tended to be higher than that of the control group after parturition and was significantly so between days 0 to 30 ( $\mathrm{p}<0.05$; Fig. 1). The plasma Glu concentration of the trimmed group was significantly higher than that of the control group between days 0 to 30 , days 31 to 60 and days 61 to 120 ( $p<0.05$; Table 2). The concentrations of plasma T-chol and UN were not significantly differ between the groups. The concentration of plasma NEFA was significantly higher in the trimmed group between days -30 to $-1(\mathrm{p}<0.05)$. In contrast, the plasma NEFA concentration was significantly higher in the control group between days 0 to $30(\mathrm{p}<0.05)$. In the control group, the plasma cortisol concentration was highest between days -30 to -1 and lowest between days 0 and 30 (Table 3 ). Thereafter, the levels gradually increased
Table 2. Comparison of the plasma glucose, total cholesterol, urea nitrogen and non-esterified fatty acid levels of the trimmed and control groups

\begin{tabular}{cccc}
\hline \multirow{2}{*}{$\begin{array}{c}\text { Milking stage } \\
\text { (days) }\end{array}$} & \multicolumn{2}{c}{ Groups } \\
\cline { 2 - 4 } & Trimmed & Control \\
\hline $\mathrm{Glu}$ & -60 to -31 & $55.6 \pm 7.4$ & $55.8 \pm 4.5$ \\
$(\mathrm{mg} / \mathrm{d} l)$ & -30 to -1 & $66.0 \pm 4.1$ & $58.6 \pm 4.6$ \\
& 0 to 30 & $56.3 \pm 2.5^{*}$ & $42.5 \pm 9.7$ \\
& 31 to 60 & $57.8 \pm 6.2^{*}$ & $47.2 \pm 9.2$ \\
$\mathrm{~T}-\mathrm{chol}$ & 61 to 120 & $62.6 \pm 4.3^{*}$ & $51.7 \pm 4.0$ \\
$(\mathrm{mg} / \mathrm{d} l)$ & -60 to -31 & $116 \pm 17$ & $153 \pm 58$ \\
& -30 to -1 & $84 \pm 12$ & $105 \pm 28$ \\
& 0 to 30 & $132 \pm 20$ & $90 \pm 19$ \\
$\mathrm{UN}$ & 31 to 60 & $197 \pm 27$ & $185 \pm 25$ \\
$(\mathrm{mg} / \mathrm{d} l)$ & 61 to 120 & $206 \pm 39$ & $208 \pm 40$ \\
& -60 to -31 & $9.6 \pm 2.5$ & $10.5 \pm 3.0$ \\
& -30 to -1 & $11.5 \pm 1.3$ & $12.3 \pm 3.9$ \\
& 0 to 30 & $11.2 \pm 2.9$ & $9.5 \pm 2.0$ \\
$\mathrm{NEFA}$ & 31 to 60 & $14.1 \pm 3.4$ & $12.6 \pm 1.8$ \\
$(\mu \mathrm{Eq} / l)$ & 61 to 120 & $14.0 \pm 3.3$ & $13.8 \pm 3.9$ \\
& -60 to -31 & $111 \pm 27$ & $182 \pm 188$ \\
& -30 to -1 & $226 \pm 92^{*}$ & $111 \pm 64$ \\
& 0 to 30 & $268 \pm 124 *$ & $576 \pm 274$ \\
& 31 to 60 & $294 \pm 150$ & $129 \pm 55$ \\
& 61 to 120 & $82 \pm 29$ & $104 \pm 34$ \\
\hline
\end{tabular}

Values are expressed as means \pm SD.

*: Significant difference between the groups $(\mathrm{p}<0.05)$.

Glu: glucose. T-chol: total cholesterol. UN: urea nitrogen. NEFA: non-esterified fatty acids.

Table 3. Comparison of the plasma cortisol and insulin levels and glucose disposal rates of the trimmed and control groups

\begin{tabular}{|c|c|c|c|}
\hline \multirow{2}{*}{ Variable } & \multirow{2}{*}{$\begin{array}{l}\text { Milking stage } \\
\text { (days) }\end{array}$} & \multicolumn{2}{|c|}{ Groups } \\
\hline & & Trimmed & Control \\
\hline Cortisol & -60 to -31 & $2.94 \pm 1.23$ & $4.78 \pm 4.48$ \\
\hline \multirow[t]{4}{*}{$(n \mathrm{~g} / \mathrm{m} l)$} & -30 to -1 & $5.35 \pm 4.03$ & $10.71 \pm 7.28$ \\
\hline & 0 to 30 & $3.93 \pm 2.04$ & $2.90 \pm 0.26$ \\
\hline & 31 to 60 & $5.31 \pm 2.26$ & $6.28 \pm 6.12$ \\
\hline & 61 to 120 & $5.06 \pm 5.05$ & $9.89 \pm 6.96$ \\
\hline Insulin & -60 to -31 & $1.34 \pm 0.75$ & $1.08 \pm 0.41$ \\
\hline \multirow[t]{4}{*}{$(n \mathrm{~g} / \mathrm{m} l)$} & -30 to -1 & $1.15 \pm 0.69$ & $0.88 \pm 0.45$ \\
\hline & 0 to 30 & $0.32 \pm 0.07$ & $0.25 \pm 0.06$ \\
\hline & 31 to 60 & $0.52 \pm 0.19$ & $0.53 \pm 0.28$ \\
\hline & 61 to 120 & $0.83 \pm 0.32$ & $0.59 \pm 0.15$ \\
\hline GDR & -60 to -31 & $36.4 \pm 10.8$ & $27.6 \pm 16.2$ \\
\hline \multirow[t]{4}{*}{$(\%)$} & -30 to -1 & $36.8 \pm 7.7$ & $37.0 \pm 6.5$ \\
\hline & 0 to 30 & $50.1 \pm 4.5^{*}$ & $38.1 \pm 8.8$ \\
\hline & 31 to 60 & $45.4 \pm 3.6$ & $43.7 \pm 9.2$ \\
\hline & 61 to 120 & $39.8 \pm 8.3$ & $44.0 \pm 8.6$ \\
\hline
\end{tabular}

*: Significant difference between groups $(\mathrm{p}<0.05)$ GDR: Glucose disposal rate.

until day 120. In contrast, the plasma cortisol concentration of the trimmed group remained low throughout the experimental period. The plasma insulin concentration was not significantly different between the groups throughout the experimental period. However, the GDR of the trimmed group was significantly higher than the control group between days 0 and $30(\mathrm{p}<0.05)$. 
Hoof disease has been reported to have a deleterious effect on reproductive status [5]. However, there was no difference in reproductive status in the present study, so we could not uncover any relation between hoof trimming and reproductive status after parturition. Daily milk yield after parturition was significantly higher in the trimmed group compared with the control group. It has been reported that metabolizable energy is more preferentially used for milk production and body condition than reproduction after parturition in dairy cows [11]. Nishimori et al. reported that hoof trimming during the mid to late lactation period does not affect milk yield, but that the milk fat and protein concentrations are higher [12]. These results support the hypothesis that hoof trimming before the dry period has a more positive effect on milk yield than on weight gain or reproductive status.

The plasma Glu concentration of the trimmed group was significantly higher than that of the control group between days 0 to 120 . The plasma Glu concentration is regulated by complex interactions among endocrine, metabolic, nervous and enzymatic functions. In particular, insulin plays a dominant role in Glu regulation and is the only hormone capable of decreasing the plasma Glu concentration. After feeding on large amounts of water-soluble carbohydrate, the plasma Glu concentration is elevated via increased levels of propionic acid in the rumen, and thus the plasma Glu concentration can be used as a reference index of water-soluble carbohydrate intake in cows [12]. On the other hand, it is well known that stress elevates the plasma Glu concentration. However, the plasma cortisol concentration of the trimmed group did not increase after parturition in the present study. This suggests that the higher concentration of plasma Glu in the trimmed group was caused by increased water-soluble carbohydrate intake after parturition. Decrease of insulin sensitivity has been reported in cows during the early lactation period [17]. Kronfeld et al. [8] showed that insulin administration reduce the milk yield of dairy cows. Lactating ewes fed a restricted diet have also been found to lose weight and to have a decreased GDR [16]. Furthermore, reduction of insulin sensitivity during early lactation in cows results in reduced keratin formation of the hoof via diminished absorption of Glu and amino acids [17]. In the present study, the GDR between days -60 to -31 tended to be high in the trimmed group, and the plasma Glu concentration and GDR of this group between days 0 and 30 were significantly higher than that of the control group. These results indicated that hoof trimming before the dry period maintains glucose homeostasis during the perinatal period.

The plasma NEFA concentration is a useful indicator of energy balance in dairy cows. Milk yield increases and then peaks between 4 to 6 weeks after parturition. However, dry matter intake (DMI) recovers later, between 10 to 12 weeks after parturition. An increasing plasma NEFA concentration is the result of loss of body fat due to a negative energy balance (NEB) between energy consumption and intake [18], while increased energy consumption results in poor reproductive performance and fatty liver [6]. Increased plasma NEFA concentrations, meanwhile, can cause abnormal glucose tolerance as a result of insulin-hyposensitivity in the liver [16]. To prevent such problems, it is important to increase DMI after parturition. In the present study, the increase in plasma NEFA concentration between days 0 and 30 in the control group may have been caused by NEB as a result of decreased feed intake. In contrast, because the cows of the trimmed group were prevented from having an NEB, their plasma NEFA concentrations were low after parturition.

The higher concentrations of plasma cortisol between days -30 and -1 in the control group were attributed to increased stress due to instability that was exacerbated by the weight of the growing fetus during late pregnancy. In contrast, the plasma cortisol concentration was stable before and after parturition in the trimmed group. These findings indicate that hoof trimming before the dry period reduces the stress on cows after parturition. We propose that trimming hooves of cows results in more efficient glucose utilization and improvement of their nutritional condition during the dry period and that this may minimize postpartum damage.

In conclusion, hoof trimming before the dry period may be an efficient means of reducing overall stress and maintaining nutritional condition after parturition in dairy cows. Furthermore, hoof trimming might be an effective method of increasing milk yield.

ACKNOWLEDGMENT. This study was partially supported by a Kitasato University Grant for the Encouragement of Young Scientists.

\section{REFERENCES}

1. Dobson, H. and Smith, R. F. 2000. Anim. Reprod. Sci. 60-61: 743-752.

2. Enevoldsen, C., Grohn, Y. T. and Thysen, I. 1991. J. Dairy Sci. 74: 1284-1298.

3. Fjeldaas, T., Sogstad, A. M. and Osteras, O. 2006. Prev. Vet. Med. 73: 255-271.

4. Hernandez, J. A., Garbarino, E. J., Shearer, J. K., Risco, C. A. and Thatcher, W. W. 2005. J. Am. Vet. Med. Assoc. 227: 12921296.

5. Hultgren, J., Manske, T. and Bergsten, C. 2004. Prev. Vet. Med. 62: 233-251.

6. Kim, I. H. and Suh, G. H. 2003. Theriogenology 60: 1445 1456.

7. Kohiruimaki, M., Ohtsuka, H., Hayashi, T., Kimura, K., Masui, M., Ando, T., Watanabe, D. and Kawamura, S. 2006. J. Vet. Med. Sci. 68: 935-940.

8. Kronfeld, D. S., Mayer, G. P., Robertson, J. M. and Roggi, F. 1963. J. Dairy Sci. 46: 559-563.

9. Kumari, G. L. and Dhir, R. N. 2003. J. Immunoassay Immunochem. 24: 173-190.

10. Lovendahl, P. and Purup, H. M. 2002. J. Anim. Sci. 80: 191195.

11. Lucy, M. C. 2001. J. Dairy Sci. 84: 1277-1293.

12. Nishimori, K., Okada, K., Ikuta, K., Aoki, O., Sakai, T. and 
Yasuda, J. 2006. J. Vet. Med.Sci. 68: 267-270.

13. Ohtsuka, H., Koiwa, M., Hatsugaya, A., Kudo, K., Hoshi, F., Itoh, N., Yokota, H., Okada, H. and Kawamura, S. 2001. J. Vet. Med. Sci. 63: 1021-1025.

14. Shearer, J. K. and van Amstel, S. R. 2001. Vet. Clin. North Am. Food. Anim. Pract. 17: 53-72.

15. Sogstad, A. M., Fjeldaas, T. and Osteras, O. 2005. Acta Vet. Scand. 46: 203-217.

16. Sternbauer, K. and Luthman, J. 2002. Acta Vet. Scand. 43:
107-114.

17. Tomlinson, D. J ., Mülling, C. H. and Fakler, T. M. 2004. J. Dairy Sci. 87: 797-809.

18. Vandehaar, M. J., Yousif, G., Sharma, B. K., Herdt, T. H., Emery, R. S., Allen, M. S. and Liesman, J. S. 1999. J. Dairy Sci. 82: 1282-1295.

19. Vermunt, J. J. 1999. Vet. J. 157: 109-110.

20. Vokey, F. J., Guard, C. L., Erb, H. N. and Galton, D. M. 2001. J. Dairy Sci. 84: 2686-2699. 